\title{
Reference Range
}

National Cancer Institute

\section{Source}

National Cancer Institute. Reference Range. NCI Thesaurus. Code C71474.

A set of values of particular type of measurement that is used to interpret corresponding observation results. 